\title{
Spurred by Threats or Afraid of War? A Survey Experiment on Costs of Conflict in Support for Military Action*
}

\author{
Kristian Skrede Gleditsch`, Atsushi Tago ${ }^{\ddagger}$ Seiki Tanaka ${ }^{\S}$
}

\begin{abstract}
It is commonly assumed that perceived threats from a rival state will make individuals more likely to "rally-round-the-flag" and support military action. Previous studies have looked at how information about threats affects public support for military action. To date, however, there has been less attention to how information about the costs of conflict affects support for military action in response to threats. In this article, we present a survey experiment designed to evaluate how information about the likely military and economic costs of conflict influences support for military action. We provide Japanese respondents with information about relations with China, and probe how support for military action in the context of the ongoing territorial dispute changes with varying information on the military costs of conflict and its economic consequences. We find that information about trade ties and military capacity exerts a pacifying effect and strengthens opposition to military action. Consistent with our proposed mechanism, we show that greater awareness of military costs is associated with stronger opposition to military action. Our results indicate that even under the existence of external threats, greater awareness of the costs of conflict affects attitudes to military action and can increase support for peaceful solutions to territorial rivalries.
\end{abstract}

Keywords: Public opinion; territorial disputes; interdependence; arming, Japan, China

"The authors are listed in alphabetical order, equal authorship implied. We are grateful for comments from Julia Bader, Brian Burgoon, Ursula Daxecker, Songyin Fang, Katjana Gattermann, Shoko Kohama, Theresa Kuhn, Michaela Mattes, Nobuhiro Mifune, Jason Reifler, Paul Post, Spencer Piston, Andrea Ruggeri, Joep Schaper, and participants at 2017 annual meeting of the International Studies Association in Baltimore, MD, USA and the ISA International Conference in Hong Kong as well as workshops at the University of Amsterdam, Kobe University, and Yale University for comments. This project was funded by research grants from the Asahi Glass Foundation and Japan Society for the Promotion of Science. The human subject protocol of the research was evaluated by Kobe University School of Law IRB and conducted following IRB approval.

${ }^{\dagger}$ University of Essex \& Peace Research Institute Oslo, ksg@essex . ac . uk

${ }^{\ddagger}$ Waseda University, Kobe University \& Peace Research Institute Oslo, tago@waseda.jp

${ }^{\S}$ University of Leeds, S. K. Tanaka@leeds . ac . uk 


\section{Introduction}

There is an extensive literature on the so-called rally effect in public support for international military action. The core idea is that an imminent crisis or threats by a rival state will make individuals more likely to support hawkish leaders and their national security policies. A number of studies have examined how information about threats can increase the magnitude of the rally effect. Beyond threats, individual support is also likely to depend on awareness of the potential costs associated with such hawkish policies and the consequences of possible militarized conflicts. Yet, there has been little research so far on how awareness of costs affects support for belligerent actions in international crises. In this study, we argue that gaining information about bilateral relations can change individual awareness about the potential costs of militarized conflict and induce greater opposition. We take advantage of an ongoing conflict to consider a situation with external threats, and test the implication that greater awareness of the potential costs of military conflict increases opposition to military action in an experimental setting. The experimental results lend support for our argument that despite the existence of ongoing external threats, greater awareness of the costs influences individual attitudes toward military action and can increase support for peaceful solutions to international rivalries.

We conduct a survey experiment in Japan, based on a scenario with belligerent action in the highly salient territorial conflict with China, where we assess how different conditions for the costs of conflict influence individual support or opposition to hawkish foreign policies. To our knowledge, this is the first experimental study on individual support for the use of force to consider both military and economic costs, as well as the specific manner in which information is conveyed. The results indicate that awareness of military and economic costs is associated with greater opposition to military action. We also find that awareness of military costs seem to have a larger effect on attitudes than emphasizing the costs of trade disruption, suggesting that despite the presence of external threats, providing information about costly military conflict can increase support for peaceful solutions even in ongoing territorial rivalries. Finally, we find that highlighting information about costs and increasing awareness can strengthen opposition to military conflict. This provides additional support for our proposed mechanism. 
In the remainder of this article, we first discuss how external threats affect public opinion. We then introduce our novel theoretical argument that the effect of threats also depends on individual awareness about the potential costs of military action. We next turn to how the specific manner used to present information can affect individual awareness of costs, highlighting the likely effectiveness of graphical images over verbal descriptions. Lastly, we detail our experimental design and findings from the survey experiment in Japan on individual support for hawkish policies within the context of the territorial dispute with China.

\section{Argument: The Costs of Conflict and Support for Military Action}

Research on public opinion and conflict consistently finds that the public is more supportive of military action when faced with plausible external military threats. A number of mechanisms have been put forward to explain this so-called rally-round-the-flag effect. Some argue that individuals generally become more likely to support political leaders during international crises, as conflict with an out-group tends to strengthen in-group solidarity and decrease the salience of divergent opinions and preferences within groups relative to a pre-crisis situation (Mueller 1970). ${ }^{\mathrm{I}}$ Relatively more secure popular support during a crisis increases the likelihood that leaders will respond to threats with military action (Colaresi 2004, Vasquez 2009). Since disputes in general trigger nationalism, and in particular in territorial disputes (Fravel 2005, Gibler 20I2, Tanaka 2016, Tir 2010), leaders may face costs for not threatening to resort to military action or being seen as overly dovish, while others argue that leaders have personal incentives to adopt more hawkish foreign policies during crises in order to try to increase their support or divert attention from other issues (Tir 2010). ${ }^{2}$

Existing research has focused on a number of factors that make support for military action more likely

\footnotetext{
'There are strong grounds to suspect that support is conditional on the magnitude and plausibility of the external threats (Lai and Reiter 2005). In the context of more "domestic" security threats, Getmansky and Zeitzoff (20I4) find that Israeli voters become more likely to support hardline parties on the right when the range of missiles launched by Palestinian groups extends so that individuals are at risk of becoming a victim in their locale.

${ }^{2}$ Given their high salience, territorial disputes may create more opportunities for elites to mobilize the public. The degree of mobilization is also dependent on the narratives elites use - see Zellman (2015) for experimental findings.
} 
in the presence of external threats. Many have studied the role of the domestic media in whether threats translate to support or not (e.g., Baker and Oneal 2001, Baum 2002, Groeling and Baum 2008). However, there has been little attention so far to whether the likely costs of conflict can affect the extent of popular support for military action, even in the presence of plausible external threats. In this article, we argue that support for military action via such plausible threats can be dampened when individuals become aware of the costs associated with military action.

Our research is timely as our study case, Japan, is currently facing missile threats from North Korea. If we only consider the conventional wisdom on the effect of threats, we should expect that Japanese citizens should be more willing to support military action — and possibly pre-emptive action — against North Korea. By contrast, we argue that once we factor in if people perceive the costs of military action to be high, they will be less likely to support such measures. Although it is intrinsically difficult to disentangle the effect of perceived costs from external threats, experimental settings allow us to isolate the effect of former. We explain our experimental design in more detail below, but in the next section, we first elaborate our argument and consider two specific costs of war, namely the likely negative economic and military consequences of conflict.

\section{Economic and Military Consequences of Conflict}

We have a great deal of existing evidence suggesting that greater trade interdependence can reduce the likelihood of military conflict. A number of comparative studies show that greater interdependence and economic ties between states appear to have a pacifying effect on the risk of military conflict between states due to the expected economic opportunity costs of military action (Gartzke and Li 2003, Mansfield and Pollins 200I; 2003, Oneal et al. 1996, Oneal and Russett 1997, Rosecrance 1986, Russett and Oneal 200I, Rummel 1983; 1985, Schneider and Gleditsch 2013, Xiang, Xu and Keteku 2007). Although some studies cast doubt on the relative importance of interdependence against other liberal factors such as democracy (e.g., Dafoe 20II), more recently, Tanaka, Tago and Gleditsch (20I7) provide experimental evidence that citizens become less likely to support military action when they are provided with information about 
trade interdependence, consistent with the idea that the likely economic consequences of conflict can decrease individual support for the use of violence.

However, the total costs of military conflict go beyond the economic opportunity cost. We argue that the degree of arming and plausible risk of extended military conflict should have similar pacifying effects on individual public opinion. Most existing work on arming have focused on the incentives of leaders to arm in the presence of perceived threats from other states and the desire to deter the opponent from aggression (Jervis 1978, Rider, Findley and Diehl 20II). However, arming is itself costly, and the consequences are ambiguous; deterrence may fail, and arms races may increase the risks of military conflict (Gibler, Rider and Hutchison 2005, MaOz 1990, Rider 2009). Accordingly, if individuals are sensitive to the potential risk of conflict and more risk averse than leaders, they should be less likely to support belligerent policies that risk escalation and arms races, and when the potential costs of conflict are high (Levy 1992; 1997, de Heus, Hoogervorst and van Dijk 2010). This is especially the case as ordinary citizens are likely to incur a disproportionate share of the war-related costs compared to elites (Reiter and Tillman 2002). For instance, militarized conflicts may result in direct costs such as displacement, casualties, and infrastructure damage, as well as indirect costs such as higher taxes. ${ }^{3}$ Thus, we should expect that greater information about higher arming will make individuals more likely to oppose belligerent policies as they are concerned about the risk of possible militarized confrontation and its costs. Our primary interest in this article is to demonstrate that two types of perceived costs of conflicts - loss of trade and costs of arming - both decrease the support among respondents for the government's belligerent action. However, because arming can potentially be more destructive and lead to higher costs of conflict than trade disruption, ${ }^{4}$ we expect that the pacifying effect of arming will be higher than the impact of trade disruption.

Our argument also has implications for the literature on public opinion and international conflict. Leaders may have incentives to respond to external threats with military action during crises (Colaresi

${ }^{3}$ Flores-Macías and Kreps (forthcoming) provide experimental evidence indicating that citizens are less likely to support military interventions if the government pays for them through taxation rather than borrowing.

${ }^{4} \mathrm{Also}$, all else equal, arming raises the baseline costs of conflict, while trade disruption does not have the feature - a conflict leads to a loss of the current level of economic activities. 
2004, Vasquez 2009), but threats can have the opposite effect if individuals also perceive higher warrelated costs. Our argument suggests that even if leaders themselves are not deterred by external threats, we can have more significant public opposition to aggressive policies if there is widespread awareness of the potential costs of these policies. ${ }^{5}$ Both economic opportunity costs and military-arming costs can only influence military action through public opinion if individuals are aware of the likely costs.

\section{Information, Images, and Attitudes}

We have so far argued that awareness of potential costs of military action will make individuals more likely to oppose the government's military action. The main assumption here is that public opposition to military action by the government requires that individuals are aware of the costs. It is thus natural to believe that the way the information is provided matters for the extent to which people are aware of the potential costs of military action, thereby affecting the degree of opposition to military action. Scholars have discussed how the use of information can moderate hawkish public attitudes in international crises (Levendusky and Horowitz 20I2, Quek and Johnston 2018). Our study also contributes to existing research through highlighting how the degree of awareness also affects the effect of information on public opinion.

Even if our argument is plausible and internally consistent in the sense that it would hold in a population of rational and informed actors, there are several challenges for the mechanisms to operate for actual individuals in real life settings. For example, many people with limited interests in politics may not know much factual information regarding trade and arming, and hence have little basis for assessing the potential costs of military action. Additionally, individuals may find it difficult to link information on trade and arming to the potential costs of military action. Humans also have limited cognitive abilities, and often find it difficult to understand or process information about complex issues (e.g., Berinsky 2007). Baker

\footnotetext{
'This is reminiscent of the focus on the costs of conflict and the likelihood of successful military action in research on the democratic peace - wars against democracies are costly because they are better equipped in terms of resources and have electoral incentives to fight harder (e.g., Bueno de Mesquita, Morrow, Siverson and Smith 1999), and individuals may be aware of the costs (Tomz and Weeks 2013). Our empirical application considers opinion in a democracy on relations with an autocracy, and are hence unlikely to reflect different behavior towards other democracies.
} 
and Oneal (200I) also argue that how information is presented by media and politicians strongly influence public support for military action (see also Aday 20Io). Thus, the specific way information about the likely economic and military costs of conflict is presented should affect the degree of support for belligerent military action during crises through its effect on people's awareness of trade, arming, and the potential costs of military action. In particular, we expect that presentations that more effectively convey costs are likely to reduce support for belligerent actions among individual respondents. We believe this test provides additional evidence for our main claim that greater awareness of higher trade and arming and potential costs of military action make individuals more likely to oppose belligerent policies.

Here, we take advantage of recent findings that graphical images can convey information more effectively than just text-based presentations (Nyhan and Reifler 2016, Piston 2014), and examine whether greater awareness about the costs of military action through graphical images can decrease support for the military action. More generally, a growing body of research finds that visual images can affect people's attitudes (Mayer 2009, Moreno and Mayer 2002, Piston 2014), including attitudes toward high stake issues such as national security (Aday 20I0, Caverley and Krupnikov 20I5, Gartner 20II, Glazier and Boydstun 2013). ${ }^{6}$ For example, Caverley and Krupnikov (2015) provide experimental evidence that pictures of soldiers increase people's support for increasing military expenditure. Similarly, Hassin et al. (2007) find that providing Israeli subjects with an image of the Israeli flag influences their political attitudes and induces them to take a more centrist positions on controversial issues. Gartner (2OII) also finds that images of losing a battle affects the likelihood that people shift from supporting to opposing a conflict. ${ }^{7}$

We also use graphical images in our tests how awareness of military costs affect individuals' degree of support for military action. We expect that graphical images will increase the level of opposition to military action more effectively than text alone. ${ }^{8}$ According to Nyhan and Reifler (2016), graphical images can convey a large amount of information in a clear way so that citizens can better understand otherwise

\footnotetext{
${ }^{6}$ Information is usually processed through two separate channels in the human brain, namely auditory and visual modes (Moreno and Mayer 2002, Paivio 1986). Because humans can only process a limited amount of information in one channel at a time, engaging both of these channels facilitate information processing.

${ }^{7}$ Gartner (2OII) argues that visual presentations that have clear and familiar signals are more likely to facilitate an interpretation of information.

${ }^{8}$ There could be limits to such effects. For example, Valentino, Hutchings and White (2002) point out that presentations that are too explicit about sensitive topics such as race in the US are unlikely to elicit truthful answers.
} 
more complex and difficult information. In addition, graphical images are considered to be more effective in conveying trends or changes in quantities over time (Nyhan and Reifler 2016, Piston 20I4). ${ }^{\text {These }}$ studies suggest that graphical presentations combined with texts can increase people's awareness of accurate information of interest. ${ }^{\text {IO }}$ From this, we argue that adding a visual presentation with a graph should increase the impact of information about the likely costs of militarized conflicts on support for military action.

In sum, our expectations can be summarized as the following hypotheses:

Ho: Greater awareness of the likely costs of conflict decreases individual support for hawkish action by the government toward a rival country.

HI: Providing information about costs of arming decreases individual support for hawkish action more than about opportunity costs of trade.

H2: Providing information about costs in a graph decreases individual support for hawkish action more than in a text description alone.

Tanaka, Tago and Gleditsch (20I7) have already demonstrated plausible support in favor of Ho, and our analysis is not designed to test this. Rather, we use Ho as a baseline assumption, and then focus on testing what kind of information could lead to a decline in support for the government's hawkish action through raising awareness of the likely costs (i.e., $\mathrm{H}_{\mathrm{I}}$ and $\mathrm{H}_{2}$ ). More specifically, we test the hypotheses by using a survey experiment in the context of the enduring rivalry and territorial disputes between Japan and China over the disputed islands Senkaku/Diaoyu. This is an appropriate test case since there is a clear

\footnotetext{
${ }^{9}$ More specifically, Nyhan and Reifler (2016) find that graphical presentations of information can correct people's misperceptions, and Piston (2014) demonstrates that individual's ignorance can be mitigated by providing visual images, thereby affecting political decisions.

${ }^{10}$ This does not exclude other ways of increasing public awareness of costs of military action such as pictures, but we believe that a graphical presentation is the best way to estimate the perceived costs, while controlling for other factors in the treatment presentation.
} 
rivalry and plausible threat of military action between the two countries, but many individuals may be relatively ignorant of the likely costs of conflict.

Japan's recent defense white paper makes it clear that the Japanese government still views China as a military threat, referring "to Beijing's heavy-handed efforts to increase its military presence in the East China Sea and South China Sea" (Asabi Shinbun, August 2, 2016). China immediately responded with strong condemnation and reiterated their claim to the disputed islands (Washington Post, August 3, 2016). Despite recent development on North Korea's missile crises, several expert interviews suggest that the Japanese continue to consider China as the primary threat (Reuters, March 20, 2018).

It is also clear that Japanese public opinion bas been generally very negative toward China, in particular since Japan's "nationalization" of the uninbabited Senkaku/Diaoyu islands (Iida, Kobno and Sakaiya 20I2). The Chinese public has also expressed negative attitudes toward Japan, including many anti-Japanese demonstrations following the announcement of the "nationalization." This antagonistic sentiment should suffice to create a baseline rally effect among Japanese public. Tanaka, Tago and Gleditsch (20I7) demonstrate that Japanese public opinion toward China is indeed generally very bostile, and that respondents are generally likely to support belligerent actions by the government on the Senkaku/Diaoyu islands.

An experiment is useful to test our argument. Randomly providing information that primes association between military action and costs allows us to isolate the effect of perceived costs on individual support for the use of force, holding other factors such as external threats constant or independent of the treatment. In the next section, we present our experimental design for examining whether providing relational information can mitigate the baseline hawkish attitudes. 


\title{
Empirical Analysis
}

\author{
Survey Design
}

To test the hypotheses, we designed an original survey experiment and conducted it in Japan with a sample of I,46I Japanese adults in July 20I5. ${ }^{\text {II }}$ The sample was drawn by a Japanese survey firm, Nikkei Research, from their opt-in online panel. ${ }^{12}$ This is a non-probability sample, but we attempted to sample based on three key demographic variables (i.e., age, gender, and residential locations) to ensure that the sample would resemble as closely as possible the general population.

We provided all respondents with a bypothetical scenario with a belligerent act by the Japanese government in the ongoing territorial disputes between Japan and China over the Senkaku/Diaoyu islands and asked respondents whether they would support or oppose it. More specifically, respondents were told that "Today, the Japanese government decided to station SDF (Self-Defense Forces) destroyers on the Senkaku islands." They were then asked "Do you approve of the Japanese government's decision?" on a s-point scale: 5 (strongly agree), 4 (somewhat agree), 3 (neither), 2 (somewhat disagree), I (strongly disagree).14

Given the current and historical strained relationship between the two countries, we expect to find that many Japanese respondents support the belligerent action and that the baseline approval rate should be high. However, despite the baseline hawkish attitudes, we also expect that providing trade or arming information about the relationship between two countries will dampen support for military action and make respondents less likely to support the belligerent decision, through linking the belligerent action to its potential costs. We believe Japanese respondents should be able to associate this kind of information about relationships with costs of hawkish action. For example, in 20I2, a diplomatic incident between Japan and China, induced

\footnotetext{
${ }^{\text {II }}$ The approval rate for the government was slightly lower (41\%) in July 2015 than the 2015 average (46\%). We will discuss below whether respondents just approved or opposed the government rather than reacted to our treatments. The information is based on the monthly polls of the Japan Broadcasting Corporation, see http://www . nhk . or . jp/bunken/research/ yoron/political/2015.html.

${ }^{\text {I2 }}$ Respondents were invited by the company to participate in the survey about international relations. Those who agreed to participate answered questions on the company's survey website. The response rate was 5.9\%.

${ }^{13}$ Johns and Davies (20I2) use a similar hypothetical sentence.

${ }^{14}$ As the Japanese government mainly uses coastal guards and do not have stationed military forces to patrol the islands, the hypothetical decision should be considered a belligerent action.
} 
by the Japanese government's hawkish action, led Chinese customers to boycott Japanese products. Bilateral trade between the two countries dropped by $3.9 \%$, and the national media propagated related news items for a long time (Japan Times, January II, 20I3). We thus expect that providing information about trade and arming between the two countries induces respondents to become more aware of costs associated with a bypothetical military action.

All the respondents received such stimulus information right before the bypothetical scenario was presented, but the specific information each respondent received varies. Respondents were randomly assigned to one of four treatment groups. In all the treatment groups, we inserted information about a relationship between Japan and China (i.e., trade or arming) in the context of the territorial disputes. Because the relationship information alone may not be sufficient to prompt respondents to associate the information with costs of hawkish action, we also provided information on trends in the relationship (i.e., trends in trade or arming), thereby facilitating the association. By exposing respondents to such information, the survey experiment was intended to test whether providing information about a relationship with a rivalry (i.e., China) and triggering awareness of likely costs of military conflict enbances or reduces support for the Japanese government's aggressive action. ${ }^{\mathrm{IS}}$

More specifically, based on our above-mentioned argument, the survey experiment was implemented via two sets of cross-cutting treatments (i.e., $2 \times 2=4$ treatment groups). In the first two treatment groups, we exposed respondents to either information about the extent of trade interdependence or levels of arming. We used a similar number of words for both of the information so as to control for a possible framing effect due to the length of the text. Further, since each script including the stimulus information as well as the bypothetical scenario consists of three different sentences in total, adding a conjunction - e.g., therefore, despite, and however - between the sentences may mislead some respondents to answer in a certain way. To avoid this, we presented the three sentences without any conjunction. ${ }^{16}$ The specific information content and

\footnotetext{
${ }^{\text {Is }}$ An alternative experimental design could be to try to make individuals directly assess costs of military action. However, a major downside is that it would be difficult to elicit truthful answers from respondents. If the connection is too obvious and direct, they may try answer in a way that believe to be desired rather than based on actual preferences. Thus, we see our approach to provide information about trade ties or arming in order to trigger perception of likely costs of military action as more appropriate.

${ }^{16}$ We thank (anonymous) for the suggestion. Although Berinsky and Kinder (2006) propose that providing information in a context of a good story helps people understand complex issues, we believe that since our study deals with a much simpler
} 
wordings follow our previous study (anonymous). For example, the respondents in the arming treatment saw the following sentences: "China is a potential military threat to Japan, and Japan is also a potential military threat to China. Both China and Japan have dramatically increased the amount of military expenditures since 2008. Today, the Japanese government decided to station SDF (Self-Defense Forces) destroyers on the Senkaku islands.”

The respondents in the trade interdependence treatment saw the followings: "China is the top trading partner of Japan, and Japan is also the top trading partner of China. Both China and Japan have dramatically increased the quantity of exports and imports to each other since 2008. Today, the Japanese government decided to station SDF (Self-Defense Forces) destroyers on the Senkaku islands."

To be precise, each treatment group was presented with two different types of information: one about the relationship between Japan and China in terms of either military expenditure or trade interdependence, and another about the trends in the relationship. Thus, any change in respondents' attitudes due to a treatment can be attributed to either the relationship information effect or the trend information effect. Yet, Tanaka, Tago and Gleditsch (2017) find no evidence that bighlighting trends in interdependence between two countries has a greater effect on individual attitudes than levels. Accordingly, we assume that the latter trend information does not affect the respondents' perception directly, but rather belps respondents process the information of relationship between Japan and China.

It is also important to note that the information we provided in both trade and arming does not directly mention costs associated with the military action. In the trade treatments, by providing information about significant amount of trade between Japan and China, we suggest that the bypothetical military action is likely to disrupt the trade relationship and result in large economic opportunity costs. Similarly, in the arming treatments, by providing information about the intensity of military rivalry between Japan and China, we suggest that the military action by the government is likely to lead to more severe militarized conflicts between the two countries and result in large conflict-related costs. In this sense, the military expenditure, or budgetary costs, per se in the experimental scenario is not the costs we intend to test; rather, the military expenditure is a way to raise people's awareness of potential costs associated with subsequent subject, the sentences without a conjunction lead to relatively neutral framing as well. 
military action.

In terms of our theoretical expectations, we expect that trade interdependence increases individual awareness about greater opportunity costs, and make respondents more likely to oppose hostile actions. Similarly, we expect that despite the current hostile relationship between the two countries and existence of actual external threats, the arming information will dampen bawkish attitudes due to concerns about likely costs derived from a possible militarized conflict and subsequent economic recession, and respondents are more likely to oppose the government action. However, since arming may be perceived to be more costly than loss of trade, we expect that the pacifying effect of arming is higher than the impact of trade.

Further, to test the implications of our main claim, we emphasize the information provided in the trade and arming treatments, and expose some respondents to a graphical image that illustrates the trends in the relationship, i.e., either military expenditures or trade interdependence. In order to identify the added effect of visual information, the respondents in the graphical image treatment groups also get the same text information as well. Figure I shows the example of the graphs - the left panel illustrates an increasing trend in military expenditure of Japan and China, and the right panel shows an increasing trend in trade interdependence between the two countries. To control for other factors in graphs, we used the same graphs for both panels, and only the texts in the graphs differ (e.g., "amount of military expenditure" and "amount of trade" on the $Y$-axis). ${ }^{17}$

\footnotetext{
${ }^{17}$ The number of the trade graph reflects actual information of trade interdependence between Japan and China, while the number of the defense graph is not based on actual military expenditure information. However, it is still a fact that the military expenditure in both countries has increased over time, and the graph clearly conveys an arms race between Japan and China.
} 
Figure I: Figure Treatments

(a) Defense Figure

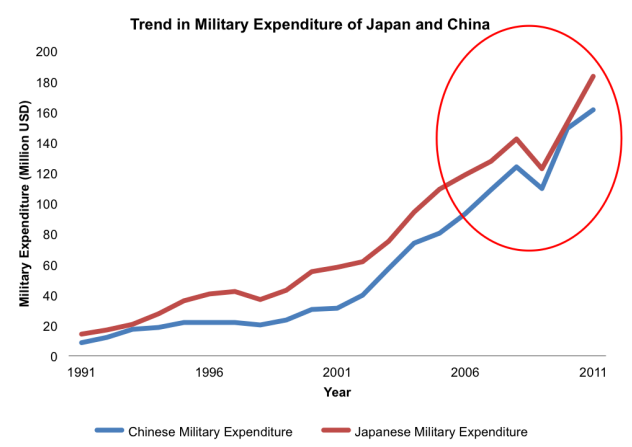

(b) Trade Figure

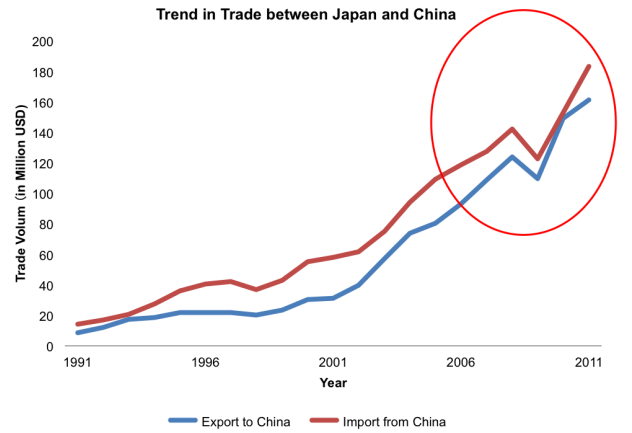

Since respondents already received the relationship and trend information in text, the graph may not contain much additional information - the graph conveys the same information as the first and second sentences above. ${ }^{18}$ However, following the literature, we believe that a graph in combination with a text boosts the impact of the textual information. Thus, our theoretical expectations bave the same direction as the text only treatment, but we expect larger effects for the graphical treatments. Note that our goal here is not to test whether particular types of visual presentations lead to different effects on people's attitudes; rather, drawing on Nyban and Reifler (2016) and Piston (2014), we aim to examine the implications of our central claim - whether greater awareness of costs associated with military action via a graphical presentation is more likely to increase the opposition to the action.

In sum, with the $2 \times 2$ cross-cutting treatments, we have four different treatments in total and randomly assigned one of the treatments to the sample. Table I shows the list of the treatment groups. Table $A$ in the Appendix confirms that randomization bas succeeded in generating balanced treatment groups across relevant demographic indicators of age, gender, education level and income level. Given previous the findings of previous studies that information about economic interdependence reduces support for military action (Tanaka, Tago and Gleditsch 20I7) - consistent with Ho -, we consider the text only treatment about trade

\footnotetext{
${ }^{18}$ To be precise, the graph provides more information such as the exact numbers of trade amount and military expenditure, thereby reducing respondents' uncertainty over the information. But we believe that this still is consistent with our expectation that increased awareness of military costs (partly due to the reduced uncertainty) increase opposition for military action.
} 
(i.e., $T_{4}$ ) as our reference group.

Table I: Summary of treatment groups

\begin{tabular}{cccc}
\hline \hline Group & Defense & Trade & Figure \\
\hline Ti: Defense (figure) & $\checkmark$ & & $\checkmark$ \\
T2: Defense (text) & $\checkmark$ & & \\
T3: Trade (figure) & & $\checkmark$ & $\checkmark$ \\
T4: Trade (text) & & $\checkmark$ & \\
\hline
\end{tabular}

\section{Covariates}

In addition to the experimental treatment, the survey also includes basic demographic questions including key individual covariates such as age, education, income level, and political affiliations. In particular, scholars find that partisanship influences how (visual) information affects public opinion about international conflicts (Caverley and Krupnikov 20I5, Gartner 20II). To examine the possibility that the effect of information differs by sub-population, the following analyses also use the political affliation variable and include an interaction term between a treatment and the variable in some of the specifications.

\section{Results: Treatment Effects}

Before we conduct t-tests, we first simply compare mean approval rates by our four treatment groups. Figure 2 indicates that the Defense (figure) treatment (TI) has the most pacifying effect $\left(\mu_{T 1}=3.92, S D_{T 1}=1.32, N_{T 1}=354\right)$. The Defense (text) treatment has the second most pacifying effect $\left(\mu_{T 2}=4.08, S D_{T 2}=1.23, N_{T 2}=324\right)$, while the treatment in the Trade (figure) group has a similar effect $\left(\mu_{T 3}=4.10, S D_{T 3}=1.25, N_{T 3}=323\right)$. Finally, our reference group, the Trade (text) treatment, has the smallest pacifying effect on respondents' attitudes $\left(\mu_{T 4}=4.18, S D_{T 4}=1.28, N_{T 4}=290\right)$. Three key findings emerge from this initial exploration. First, 
the results show that trade information (text only) has the smallest pacifying effect on people's attitude, and that the other three treatments have larger pacifying effects relative to the reference group. Second, the defense treatments generally have larger pacifying effects than the trade treatments. Finally, the results show that graph presentations combined with text presentations have larger pacifying impacts on attitudes than text alone. ${ }^{19}$ We note that as expected, given the current strained relationship between the two countries, the mean approval rates across the four groups are relatively high (i.e., between 3.92 and 4.18). Because we use the s-point scale dependent variable, the pacifying effects we find here would be more gradual and unlikely to fundamentally overturn an individual respondent's opinion, for example, switching from support to opposition.

Figure 2: Mean Approval Rates by Treatment Groups

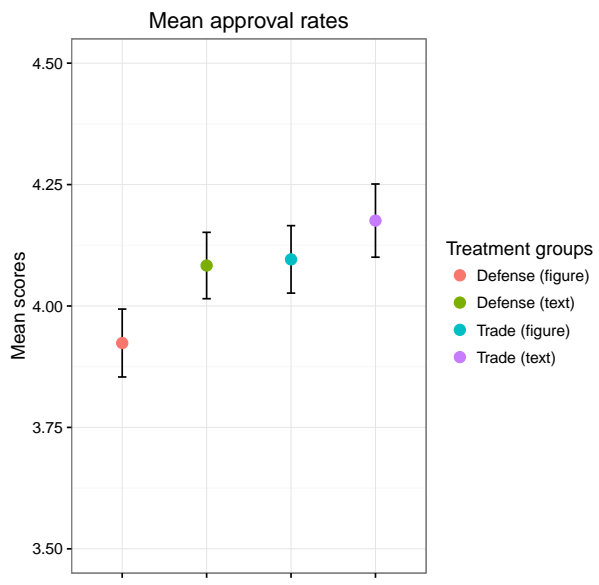

Note: The dot shows a treatment effect and the bars indicates the standard errors of the means.

To examine the initial exploration more formally, we now conduct a t-test comparing sets of treatment groups. First, we find that regardless of how the information is presented (figure vs. text), defense treatments have larger pacifying effects than the trade treatments. This is statistically significant at the 1o\% level ( $t=1.89, N=1,291)$. Second, as Figure 2 suggests, compared to any of the trade treatments (either figure or text), the Defense (figure) treatment has a statistically significant pacifying effect on people's attitude

\footnotetext{
${ }^{19}$ Some may wonder if the pacifying effect of the military expenditure treatment (figure) stems from Japanese military expenditure seemingly exceeding those of China in the figure, thus dampening public support for belligerent action. However, the fact that the direction of the effect can be observed even with the text only treatment as well as the trade treatments (both figure and text only) does not support this interpretation.
} 
and it increases the opposition level for the government bostile action toward China ( $t=1.74, N=677$; and $t=2.45, N=644$, respectively). Finally, we find that the treatment groups with a graphical presentation sees lager pacifying effects on people's attitudes than text only, and the difference between the groups is statistically significant at the Io\% level $(t=1.71, N=1,289)$. However, comparing the Defense (figure) treatment with the Defense (text) treatment is just below statistically significance at the Io\% level ( $t=1.63, N=678)$, suggesting that the effect of images is at best weakly positive for the military expenditure information. The difference between the Trade (figure) treatment with the Trade (text) treatment was not statistically significant $(t=0.78, N=613$ ).

To summarize our main findings so far, we find that (I) arming information can dampen public's hawkish attitudes more than trade information; and (2) graphical presentation can generally increase the pacifying effect of information on people's attitudes. The finding suggests that citizens can become more dovish once they are more aware of costs associated with military action. ${ }^{20}$

\section{Mechanisms}

Consistent with our claims, the evidence in combination with previous studies so far indicates that providing information about a bilateral relationship can dampen people's bawkish attitudes within the context of territorial disputes with a rivalry state. Yet, we still need to confirm whether the results are based on the expected mechanisms we laid out in the theoretical section. To specify why such bilateral information has a pacifying effect, we asked the respondents several follow-up questions about why they opposed the government's hostile decision. The number of relevant respondents is I39 for the Defense (figure) group, I03 for the Defense (text) group, IIs for Trade (figure) group, and 86 for the Trade (text) group, respectively.

First, we asked the respondents who opposed the decision whether they were afraid of possible disruption

${ }^{20}$ The awareness of political costs may also be exacerbated by so-called "negativity bias.” As a variety of psychological studies shows, human beings have a tendency to pay more attention to negative information (e.g., Baumeister, Finkenauer and Vohs 200I, Rozin and Royzman 200I). This is also true for political informational processing (e.g., Soroka 20I4). In our case, information about whether and how much one has to pay costs is naturally negative, and we expect that the information about the costs of conflicts - both arming and trade - further contributes to a decline in individual support for hawkish action by the government. Future research is needed to isolate people's opposition to costs of conflicts from such negativity bias. 
of the economic relationship between Japan and China (I: Yes; o: No). The left panel in Figure 3 summarizes the mean opposition rates. Although the graphical treatments (both defense and trade) seem to activate more concern about possible economic costs than the text alone treatments, the figure shows that regardless of the treatment group, about $40 \%$ of the respondents told that they opposed the decision due to the possible economic disruption. This suggests that bilateral relationship information (at least about arming and trade interdependence) is generally associated with individuals concerns about possible economic opportunity costs due to the government's belligerent action.

Figure 3: Reason for opposing military action

(a) Economic cost

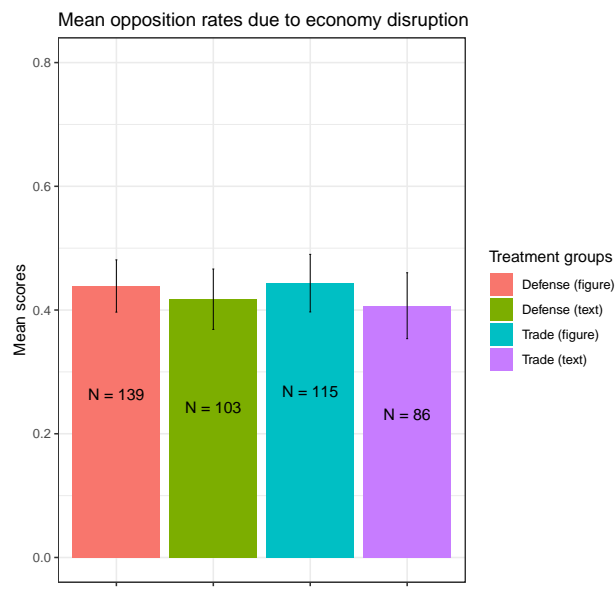

(b) Cost of adversity

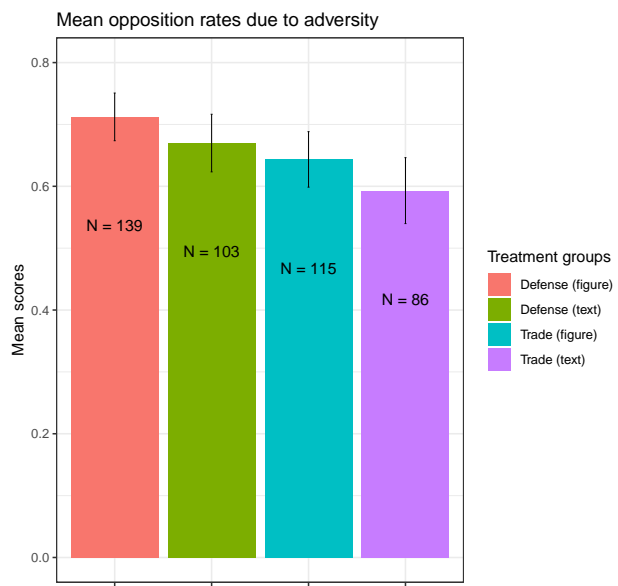

[Note: We also report the number of observations and standard errors for each bar.]

Next, we asked the same respondents whether they opposed the decision because they were afraid of increased hostility between Japan and China (I: Yes; $0:$ No). ${ }^{21}$ The right panel of Figure 3 replicates the left panel of Figure 3. According to the figure, we first find that the respondents in all the treatment groups were generally more concerned about increased hostility between Japan and China than about economic disruption. For example, even in the least pacifying treatment (i.e., Trade (text)), 18.6\% more people opposed the government's decision due to this reason, compared to the economic reason $(40.7 \% \rightarrow 59.3 \%)$. This may

${ }^{21}$ We deliberately chose a less severe outcome/concern here rather than more dramatic outcomes such as militarized conflicts, because we believe there will be more heterogeneity exists in terms of respondents' opinion about the likelihood of severe outcomes such as military confrontation. 
not be surprising because the government decision itself is already hostile, and it is natural for respondents to think that it would increase animosity between Japan and China.

But more importantly, the figure shows that the individual responses exactly mirror the opposition rates in Figure 2 - e.g., respondents in the defense (figure) treatment are the most likely to oppose the government's military action and they are the ones who are most concerned with increased adversity due to the military action. We interpret this as evidence that respondents are more likely to oppose military actions because they perceive more costs associated with the military actions and are concerned with increase adversity due to the military action. Although most of the treatment groups are not statistically significant from each other in each panel of Figure 3 (except a pair of Defense (figure) and Trade (text) in the right panel), the following two points are consistent with our interpretation. First, the defense treatments (both text and figure) cultivates more fear for increased adversity between Japan and China than the trade treatments, partly because in addition to fears of economic disruption, the arming information fuels more concern over possible military costs of the government's hostile action. Second, the figure shows that the graphical image treatments generally trigger more concern for increased adversity between Japan and China than the text treatments (this pattern can be seen in the right panel in Figure 3). This suggests that graphical presentation increases individual awareness about information (Moreno and Mayer 2002, Mayer 2009), and thus helps people think about possible costs of military action and thus in turn increase opposition for the government's bawkish action.

\section{Political Affiliation and Cost Perception}

Finally, while our main analysis offers support for our argument, we further explore an auxiliary argument, namely that approval and opposition for the government decision depends on the respondents' party affiliation. From this perspective, the likelihood of approval or opposition for the belligerent action can be intensified by an approval or opposition to the current Liberal Democratic Party (LDP) government. To consider this possibility, we estimate a model with an interaction between the experimental treatments and a reported $L D P$ affiliation variable. 
Figure 4 shows the regression result with a comparison between the defense (figure) and trade (text) treatments, which are the most and least pacifying treatments, respectively. First, the figure indeed suggests that the treatment effect of the defense (figure) varies by the characteristics of respondents. In terms of political affliation, LDP supporters are more likely to support the government's hostile decision, and this effect is statistically significant at the I\% level. By contrast, supporters for the main opposition party (i.e., Democratic Party of Japan or DPJ) are less likely to support the decision. This confirms that political affliation affects the support level of government policies. ${ }^{22}$ However, more importantly, despite the significant effect of party affiliation, the pacifying effect of the treatment (here, defense (figure)) still remains significant. Even after controlling for political affliation, providing arming information still bas a pacifying effect on individual attitudes. This suggests that even the LDP supporters can be influenced by the cost information and be less likely to support the belligerent action (note that there is no interaction effect between the treatment and LDP variables).

Figure 4: Interaction Effects with Political Affiliation: Defense (figure) vs. Trade (text)

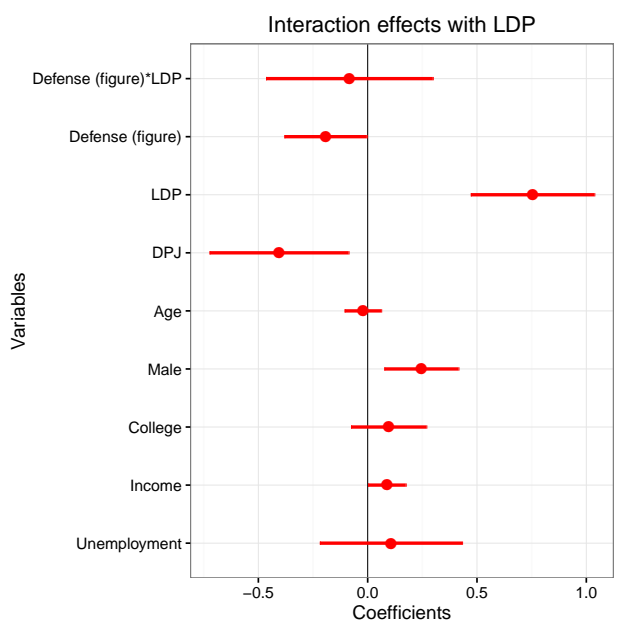

Note: The dot shows a treatment effect and the bars indicated $90 \%$ confidence intervals.

\footnotetext{
${ }^{22}$ Further, we find that male respondents and those with higher income are also more likely to support the decision.
} 


\section{Conclusion}

Despite a large number of studies of the effect of external threats, we have few systematic investigations of how individual awareness about likely military and economic costs mediates the relationship between threats and support for military action. We have argued that individuals who perceive greater costs of military action are less likely to support a leader's belligerent action, in ways that mitigate the rally effect of external threats, while those who do not should be more likely to support the leader's hawkish position in a situation with plausible threat.

Using a survey experiment in Japan on the ongoing territorial disputes with China, we examined empirical implications of the argument. Despite the high salience of the issue, the survey experiment revealed that Japanese respondents responded to information about trade ties or arming between Japan and China, and became less likely to support the government's hawkish foreign policy. We also found that providing the same information using a graphical image strengthens the pacifying effect of the information. Further analyses showed that individuals who received the information are indeed concerned with possible economic and military costs of the government's hawkish action, thereby leading to their opposition to the action.

The findings have two key implications. First, even with the presence of external threat from a rival state, public opinion can constrain hawkish leaders when people are aware of possible costs of hawkish action, even if leaders themselves are not deterred. Second, our results suggest that the substantive effect of information about levels of arming is stronger than the effects of information about economic interdependence. This indicates that it may be possible to reduce the likelibood of international conflict simply by making people recognize cost of war with arms race information, although this should be carefully assessed with similar experiments in other countries.

In particular, our experiment was conducted in Japan, where the current constitution formally renounces the sovereign right of belligerency and probibits the possession of "formal" military forces, and a recent poll suggests that about a balf of the population still prefer to maintain the "pacifist" constitution (Asabi Shinbun, May I, 2018). Thus, the Japanese may be more easily scared by arming information than other nations. For instance, in South Korea, where an arms race has been the normal state of relations for 
decades, people may be less alarmed by cost of war information. We will need further comparable research to assess whether our findings will generalize to other cases, but we believe that our study provides a useful theoretical and empirical foundation for such future comparative research. 


\section{References}

Aday, Sean. 2010. "Leading the Charge: Media, Elites, and the Use of Emotion in Stimulating Rally Effects in Wartime." Journal of Communication 60(3):440-465.

Baker, William D. and John R. Oneal. 2oor. "Patriotism or Opinion Leadership? The Nature and Origins of the 'Rally 'Round the Flag' Effect." Journal of Conflict Resolution 45(4):66I-687.

Baum, Matthew A. 2002. "The Constituent Foundations of the Rally-Round-the-Flag Phenomenon." International Studies Quarterly 46(2):263-298.

Baumeister, Roy F., Catrin Finkenauer and Kathleen D. Vohs. zooI. "Review of General Psychology." International Security $5(4): 323-370$.

Berinsky, Adam J. 2007. "Assuming the Costs of War: Events, Elites, and American Public Support for Military Conflict."Journal of Politics 69(4):975-997.

Berinsky, Adam J. and Donald R. Kinder. 20o6. "Making Sense of Issues Through Media Frames: Understanding the Kosovo Crisis.”Journal of Politics 68(3):640-656.

Bueno de Mesquita, Bruce, James D. Morrow, Randolph M. Siverson and Alastair Smith. 19g9. "An Institutional Explanation of the Democratic Peace." American Journal of Political Science 93(4):79I807.

Caverley, Jonathan D. and Yanna Krupnikov. 20I5. "Aiming at Doves: Experimental Evidence of Military Images' Political Effects." Journal of Conflict Resolution I-28.

Colaresi, Michael. 2004. "When Doves Cry: International Rivalry, Unreciprocated Cooperation, and Leadership Turnover." American Journal of Political Science 48(3).

Dafoe, Allan. 20II. "Statistical Critiques of the Democratic Peace: Caveat Emptor." American Journal of Political Science 55(2):247-262. 
de Heus, Peter, Niek Hoogervorst and Eric van Dijk. 2010. "Framing Prisoners and Chickens: Valence Effects in the Prisoner's Dilemma and the Chicken Game."Journal of Experimental Social Psychology $46(5): 736-742$.

Flores-Macias, Gustavo A. and Sarah E. Kreps. forthcoming. "Borrowing Support for War: The Effect of War Finance on Public Attitudes toward Conflict.”Journal of Conflict Resolution .

Fravel, M. Taylor. 2005. "Regime Insecurity and International Cooperation: Explaining China's Compromises in Territorial Disputes. "International Security 30(2):46-83.

Gartner, Scott S. 20II. "On Behalf of a Grateful Nation: Conventionalized Images of Loss and Individual Opinion Change in War. "International Studies Quarterly 55(2):545-56I.

Gartzke, Erik and Quan Li. 2003. "Measure for Measure: Concept Operationalization and the Trade Interdependence-Conflict Debate." Journal of Peace Research 40(5):553-57I.

Getmansky, Anna and Thomas Zeitzoff. 2014. "Terrorism and Voting: The Effect of Rocket Threat on Voting in Israeli Elections." American Political Science Review 108(3):58-604.

Gibler, Douglas M. 20I2. The Territorial Peace: Borders, State Development, and International Conflict. New York: Cambridge University Press.

Gibler, Douglas M., Toby J. Rider and Marc L. Hutchison. 2005. "Taking Arms Against a Sea of Troubles: Conventional Arms Races During Periods of Rivalry. ”Journal of Peace Research 42(2):I3I-I47.

Glazier, Rebecca A and Amber E Boydstun. 2013. "The President, the Press, and the War: A Tale of Two Framing Agendas." Political Communication 29(4):428-446.

Groeling, Tim and Matthew A. Baum. 2008. "Crossing the Water's Edge: Elite Rhetoric, Media Coverage and the Rally-Round-the-Flag Phenomenon, 1979-2003."Journal of Politics 70(4):1065-1085.

Hassin, Ran R., Melissa J. Ferguson, Daniella Shidlovski and Tamar Gross. 2007. "Subliminal Exposure to National Flags Affects Political Thought and Behavior." Proceedings of the National Academy of Sciences 104(50):19757-1976I. 
Iida, Keisuke, Masaru Kobno and Shiro Sakaiya. 20I2. "Tracking with Successive Public Opinion Surveys - The Senkaku and Takeshima Problems: What Does the Public Think of the Government's Response? [Renzoku Yoron Chosa de ou: Senkaku/Takeshima - Seifu no Taio o Kokumin wa dou Hyoka Shiteiruka]." Chuokoron $127(16): 138-145$.

Jervis, Robert. 1978. “Cooperation under the Security Dilemma." World Politics 30(2):167-214.

Johns, Robert and Graeme A. M. Davies. 20I2. "Democratic Peace or Clash of Civilizations? Target States and Support for War in Britain and the United States. ”Journal of Politics 74(4):1038-I052.

Lai, Brian and Dan Reiter. 2005. "Rally 'Round the Union Jack? Public Opinion and the Use of Force in the United Kingdom, 1948-200I." International Studies Quarterly 49(2):255-272.

Levendusky, Matthew S. and Michael C. Horowitz. 20I2. "When Backing Down Is the Right Decision: Partisanship, New Information, and Audience Costs. Journal of Politics 74(2):323-338.

Levy, Jack S. 1992. "An Introduction to Prospect Theory." Political Psychology 13(2):I7I-I86.

Levy, Jack S. 1997. "Prospect Theory, Rational Choice, and International Relations."International Studies Quarterly $4 I(I): 87-I I 2$.

Mansfield, Edward D. and Brian M. Pollins. 200I. "The Study of Interdependence and Conflict: Recent Advances, Open Questions, and Directions for Future Research.”Journal of Conflict Resolution $45(6): 834-859$

Mansfield, Edward D. and Brian M. Pollins, eds. 2003. Economic Interdependence and International Conflict: New Perspectives on an Enduring Debate. Ann Arbor, MI: University of Michigan Press.

Maoz, Zeev. 19go. National Choices and International Processes. Cambridge: Cambridge University Press.

Mayer, Richard E. 2009. Multimedia Learning. New York: Cambridge University Press. 
Moreno, Roxana and Richard E. Mayer. 2002. "Verbal Redundancy in Multimedia Learning: When Reading Helps Listening. ”Journal of Educational Psychology 94(I):156-I63.

Mueller, John E. 1970. "Presidential popularity from Truman to Johnson." American Political Science Review 64(I):18-34.

Nyban, Brendan and Jason Reifler. 2016. "The roles of information deficits and identity threat in the prevalence of misperceptions.”.

Oneal, John R. and Bruce Russett. 1997. "The Classical Liberals were Right: Democracy, Interdependence, and Conflict, 1950-1985." International Studies Quarterly 4I(2):267-293.

Oneal, Jobn R., Frances H. Oneal, Zeev Maoz and Bruce Russett. 1996. "The Liberal Peace: Interdependence, Democracy, and International Conflict, I950-1985. "Journal of Peace Research 33(I):II-28.

Paivio, Allan. 1986. Mental Representations: A Dual Coding Approach. Oxford: Oxford University Press.

Piston, Spencer. 2014. "The Political Consequences of Ignorance about Income Inequality." Presented at the 2014 Annual Meeting of the Midwest Political Science Association.

Quek, Kai and Alastair Iain Johnston. 2018. "Can China Back Down? Crisis De-escalation in the Shadow of Popular Opposition. "International Security $42(3): 7-36$.

Reiter, Dan and Erik R. Tillman. 2002. "Public, Legislative, and Executive Constraints on the Democratic Initiation of Conflict." Journal of Politics 64(3):810-826.

Rider, Toby J. 2009. "Understanding Arms Race Onset: Rivalry, Threat, and Territorial Competition." Journal of Politics 7I(2):693-703.

Rider, Toby J., Michael G. Findley and Paul F. Diebl. 2oII. "Just part of the game? Arms races, rivalry, and war." Journal of Peace Research 48(I):85-I00. 
Rosecrance, Richard. 1986. The Rise of the Trading State: Commerce and Conquest in the Modern World. New York: Basic Books.

Rozin, Paul and Edward B. Royzman. 20oI. "Negativity Bias, Negativity Dominance, and Contagion." International Security 5(4):296-320.

Rummel, Rudolph J. 1983. "Libertarianism and International Violence." Journal of Conflict Resolution $27(I): 27-7 I$.

Rummel, Rudolph J. 1985. "Libertarian Propositions on Violence within and between Nations." Journal of Conflict Resolution 29(3):419-455.

Russett, Bruce and Jobn R. Oneal. 200I. Triangulating Peace: Democracy, Interdependence, and International Organizations. New York: W. W. Norton.

Schneider, Gerald and Nils Petter Gleditsch, eds. 2013. Assessing the Capitalist Peace. London: Routledge.

Soroka, Stuart N. 20I4. Negativity in Democratic Politics: Causes and Consequences. New York: Cambridge University Press.

Tanaka, Seiki. 2016. "The Microfoundations of Territorial Disputes: Evidence from A Survey Experiment in Japan. "Conflict Management and Peace Science 33(5):516-538.

Tanaka, Seiki, Atsushi Tago and Kristian Skrede Gleditsch. 2017. "Seeing the Lexus for the Olive Trees? Public Opinion, Economic Interdependence, and Interstate Conflict." International Interactions $43(3): 375-396$.

Tir, Jaroslav. 2010. "Territorial Diversion: Diversionary Theory of War and Territorial Conflict."Journal of Politics 72(2):413-425.

Tomz, Michael R. and Jessica L. P. Weeks. 2013. "Public Opinion and the Democratic Peace." American Political Science Review 107(4):849-865. 
Valentino, Nicholas A., Vincent L. Hutchings and Ismail K. White. 2002. "Cues that Matter: How Political Ads Prime Racial Attitudes During Campaigns. ”American Political Science Review 96(I):7590.

Vasquez, Jobn A. 2009. The War Puzzle Revisited. Cambridge: Cambridge University Press.

Xiang, Jun, Xiaohong Xu and George Keteku. 2007. "Power: The Missing Link in the Trade Conflict Relationship." Journal of Conflict Resolution 5I(4):646-663.

Zellman, Ariel. 2015. "Framing Consensus: Evaluating the Narrative Specificity of Territorial Indivisibility. ”Journal of Peace Research 52(4):492-507. 


\section{Appendix}

Table A: Balance Test

\begin{tabular}{cccccc}
\hline \hline & $\begin{array}{c}\text { Defense } \\
\text { (text) }\end{array}$ & $\begin{array}{c}\text { Trade } \\
\text { (text) }\end{array}$ & $\begin{array}{c}\text { Defense } \\
\text { (figure) }\end{array}$ & $\begin{array}{c}\text { Trade } \\
\text { (figure) }\end{array}$ & $\begin{array}{c}\text { F-test } \\
\text { (p-value) }\end{array}$ \\
\hline Age & 45.63 & 45.17 & 44.57 & 45.27 & 0.752 \\
Gender & 0.46 & 0.47 & 0.52 & 0.48 & 0.467 \\
College Education & 0.48 & 0.49 & $0.5 \mathrm{I}$ & 0.55 & 0.198 \\
Income & 2.96 & 3.07 & 2.88 & 3.00 & 0.399 \\
\hline Observation & 355 & 333 & 396 & 376 & \\
\hline
\end{tabular}

